\title{
A violência na Venezuela: renda petroleira e crise política
}

\author{
Violence in Venezuela: oil rent and political crisis
}

Roberto Briceño-León 1

\footnotetext{
${ }^{1}$ Laboratorio de Ciencias Sociales de la Universidad Central de Venezuela. Apartado 47795, 1041-A, Caracas, Venezuela. bricenoleon@lacso.org.ve, bricenoleon@cantv.net.
}

\begin{abstract}
This article analyzes the changes in violence in Venezuela during the last forty years. It links the ups and downs of the oil revenues and the political crisis of the country to the changes in the homicide rates, which increased from 7 per 100 thousand inhabitants in 1970 to 12 in 1990; 19 in 1998; and 50 in 2003. The article characterizes Venezuela as a rentist society and shows its trajectory from rural violence to the beginning of urban violence, the guerilla movements of the $60 \mathrm{~s}$, the delinquent violence related to the abundance of oil revenues and the violence during the popular revolt and the sackings of 1989 in Caracas. After this, we analyze the coups d'état of 1992 and the influence the political violence exerted upon criminal violence. We describe the political and party changes in the country, their influence upon the stabilization of homicide rates since the mid-90s and their remarkable increase during the $H$. Chávez government. The article finishes with an analysis of the current situation, the official prohibition to publish statistics on homicides and with some thoughts about the perspective of greater violence in Venezuela. Key words Violence, Venezuela, Public health, Homicides, Oil, Politics
\end{abstract}

Resumo O presente artigo analisa as mudanças na violência ocorridas na Venezuela nos últimos quarenta anos, relacionadas com os altos e baixos da renda petroleira e com a crise política no país, fatos que contribuíram para um aumento nas taxas de homicídios: de 7 por cem mil habitantes em 1970 a 12 em 1990; 19 em 1998; e 50 no ano de 2003. O artigo caracteriza a Venezuela como sociedade rentista e, a partir daí, faz uma retrospecção cobrindo desde a violência rural até os inícios da violência urbana, o movimento guerrilheiro dos anos 60, a criminalidade resultando da abundância dos recursos petroleiros e a violência em decorrência da revolta popular e dos saques ocorridos em 1989 em Caracas. Em seguida são analisados os golpes de Estado de 1992 e o impacto que a violência política exerceu sobre a violência criminal. Descrevemos as mudanças politicas e partidárias no país e sua influência sobre a estabilização das taxas de homicídios em meados dos anos 90, assim como seu considerável aumento durante o governo Chávez. O artigo conclui com uma análise da situação atual, fala sobre a proibição de publicar dados estatísticos sobre homicídios e faz uma reflexão sobre a perspectiva de ainda mais violência na Venezuela.

Palavras-chave Violência, Venezuela, Saúde pública, Homicídios, Petróleo, Política 


\section{Introdução}

A violência não foi um problema importante na saúde pública da Venezuela até fins do século 20. Por várias décadas e desde quando se pôde contar com estatísticas confiáveis, as taxas de homicídios variavam entre 6 e 10 mortos por cem mil habitantes. Ainda que altas, comparadas com as de países como Argentina e Costa Rica, eram muito baixas se equiparadas às da vizinha Colômbia. Durante décadas, a Venezuela não era um país que gerava notícias nem atraía a atenção de acadêmicos, doadores ou centros de pesquisa europeus: não tinha pobreza notória, nem abundante população indígena, nem tampouco guerrilha ou violência. E era assim porque, depois da sangrenta guerra da independência e das guerras civis do século 19, o país entrou num processo de crescimento econômico, estabilidade política e melhoramento social e sanitário, o que foi possível graças ao papel dominante que a crescente renda petroleira desempenhou na economia ${ }^{1-4,4}$. A distribuição da renda petroleira significou uma transformação notável do país e um processo de construção institucional que fez a saúde pública venezuelana ser um modelo para muitos países da região ${ }^{5}$.

A situação no início deste novo século é muito diferente. Com uma taxa de homicídios próxima aos 500 mortos por cem mil habitantes, a Venezuela coloca-se entre os países mais violentos da região, um lugar pouco honroso que partilha com países de tradição violenta e recentes guerras internas como Colômbia e El Salvador.

A maior parte do século 20 venezuelano foi um período de mobilidade social ascendente e melhoramento das condições de saúde da população. Nesse período foram controladas as grandes epidemias e oferecidas educação e oportunidades de trabalho para a população de menores recursos do campo e da cidade. Também foi o período em que surgiram as instituições modernas e fortaleceu-se o Estado de Direito ${ }^{6}$. No final do século, a situação era outra.

A partir dos anos 80 , a sociedade venezuelana iniciou um processo de mudanças e crises que ainda prossegue. A sociedade tornou-se mais pobre, mais instável e mais violenta. Em duas décadas, os homicídios multiplicaram-se por dez, mas a população sequer se duplicou. O número de homicídios cometidos no país no início dos anos 80 não alcançava 1.300 mortos anuais; vinte anos depois, superou os 13.000 assassinatos.

A violência tem se tornado um dos problemas mais importantes da saúde pública na Venezuela e é o resultado da crise do modelo de sociedade exportadora de petróleo que durante sessenta anos tinha conseguido mudar o rosto do país? Um modelo que, por décadas, tornou possível a excepcional circunstância de garantir, ao mesmo tempo e de modo sustentado, melhores salários para os trabalhadores e uma taxa crescente de luxo para os empresários. Isso foi permitido pela singularidade que tem o Estado e a democracia na sociedade exportadora de petróleo ${ }^{8}$. A economia venezuelana vive da exportação de petróleo, cuja indústria aporta um terço do Produto Interno Bruto (36\% no ano 2006) e mais de $80 \%$ das divisas que ingressam no país, porém emprega menos de $2 \%$ da força total de trabalho.

Esse ingresso petroleiro chega às mãos do governo central, que o utiliza à sua vontade. $\mathrm{O}$ Estado nessa sociedade vive da renda petroleira e, portanto, é completamente autônomo do ponto de vista econômico; é um Estado que não depende da sociedade para sua existência econômica, necessita apenas das empresas petroleiras e do mercado mundial ${ }^{9}$. Trata-se de um Estado e uma sociedade "rentistas". Chamamos renda ao ingresso petroleiro, pois há duas características importantes que o definem como tal: por um lado, embora em termos reais não seja uma renda, pois não tem a qualidade de perenidade que exigia D. Ricardo ${ }^{10}$, é liquidação de um ativo, já que se trata de um recurso natural não-renovável, a sociedade o vê "como se" fosse uma renda, já que tem quase 100 anos de presença no país. E, por outro lado, tem a característica dos ganhos extraordinários que K. Marx atribuía à renda quando colocava o exemplo dos vinhos excepcionais ${ }^{11}$. Por isso, os ingressos da sociedade podem variar de uma maneira tão grande de um ano para outro, como quando se triplicaram entre 1973 e 1974 ou quintuplicaram entre 1998 e 2005 , sem que a sociedade venezuelana (nem trabalhadores, nem empresários) tivesse feito nada especial para aumentar a produtividade, pois o preço do produto não depende dos processos ou dos custos de produção, mas de outras variáveis, muitas delas tão políticas como uma ameaça de guerra no Médio Oriente.

A crise desse modelo, tão artificial como bemsucedido, mostra as transformações que tem vivido a sociedade e forma parte da história recente da saúde pública na Venezuela.

\section{Da violência rural para a violência urbana}

Entre 1926 e 1979, a Venezuela passou por uma época de grande inclusão social. Durante esse período os venezuelanos viveram cada vez melhor, 
ao longo de várias décadas os trabalhadores puderam obter ingressos que, medidos em termos reais, eram cada vez melhores que nos anos precedentes $^{12}$. Na Venezuela foram pagos, por décadas, salários superiores aos da Europa ${ }^{13}$.

Nesse processo de modernização transformaram-se também as situações de conflito: diminuiu a violência rural tradicional e apareceram outras, como a luta armada guerrilheira e a violência da abundância. A mobilidade territorial converteu a Venezuela, em menos de 100 anos, de um país rural, onde perto de 80 por cento da população morava no campo, em outro nitidamente urbano, onde, nos dias de hoje, mais de 80 por cento moram em cidades. Tal mudança espacial veio também acompanhada de uma grande mobilidade social. As famílias melhoraram suas casas e seu acesso aos serviços públicos. Seus filhos nasceram atendidos por médicos e foram educados em escolas e colégios públicos. O país viveu um importante processo de institucionalização que permitiu o fortalecimento da cidadania política e civil ${ }^{14}$.

Com essas mudanças, a violência rural diminuiu radicalmente. Por um lado, as pessoas que se sentiam em risco migraram para as cidades; por outro lado, a institucionalidade, o estado de direito e os funcionários do Estado (inspetores de malariologia, policiais e exército) chegaram aos rincões mais afastados do território. O país unificou-se e se encontrou nas migrações e no fortalecimento do Estado. O ditador Juan Vicente Gómez, que, com um regime ditatorial, governou o país durante os primeiros trinta anos do século 20, tinha conseguido acabar com as sublevações e as guerras entre "caudilhos" ou latifundiários, para converter-se, ele mesmo, em grande latifundiário e único "caudilho" da nação.

A Venezuela, que se urbanizou aceleradamente entre os anos 40 e 60, estava, ao mesmo tempo, construindo uma sociedade sem violência. Era um país que apostava no estado de direito como a resposta adequada para as necessidades de convivência e resolução de conflitos da sociedade que se modernizava.

Esse processo foi interrompido em inícios dos anos 60, quando, com a instalação da democracia, apareceu a violência política a partir da formação de um movimento guerrilheiro de base rural e muito poucas expressões urbanas. A democracia venezuelana nasceu ao mesmo tempo que triunfou a revolução cubana, e o modelo de luta guerrilheira foquista utilizado em Cuba teve muitos imitadores na América Latina. Na Venezuela, uma divisão do principal partido social democrata e uma mudança de estratégia do partido comunista permitiram o surgimento de várias frentes guerrilheiras, que receberam apoio e treinamento do governo cubano. Sua força, entretanto, foi muito breve. A guerrilha não logrou convencer os venezuelanos do seu projeto político. Para isso contribuíram as políticas reformistas do governo, financiadas com os ingressos petrolíferos, que, atendendo ao interesse das pessoas em melhorar e ascender socialmente, conseguiram isolar e debilitar a base social que poderia ter permitido a subsistência da proposta guerrilheira Também já não havia no país a presença de "caporales" e chefes civis que despertavam o ódio dos camponeses, tal como ocorria na Colômbia. Os poucos que podiam ter resistido após o primeiro impacto do petróleo, foram eliminados com a reforma agrária ou tiveram seu poder reduzido com a nova emigração rural que se deu naquele tempo.

A guerrilha foi combatida pelo exército venezuelano, mas não acreditamos que sua derrota deveuse fundamentalmente às ações militares, mas sim às reformas sociais empreendidas. A reforma agrária, a entrega de terras, os créditos para os camponeses, as escolas unitárias ou graduadas, a ação de saneamento ambiental das comunidades rurais, o programa de habitações rurais, enfim, o dinheiro do petróleo aplicado em programas sociais fez com que os camponeses aspirassem a uma vida melhor com seu trabalho e o apoio do governo, e não mediante a luta guerrilheira.

Depois que os grupos armados fracassaram na sua tentativa de sabotar as eleições presidenciais de 1963 e se deu pela primeira vez a mudança pacífica de governo de um presidente eleito para outro, ficou muito claro para o país que a violência política estava derrotada. O processo de pacificação que ocorreu nos anos e governos seguintes permitiu a incorporação segura dos antigos guerrilheiros na vida política democrática. Sua pacificação foi bem-sucedida, pois formaram partidos e participaram de eleições, e durante esse tempo não sofreram repressão pública aberta e tampouco vinganças encobertas, como padeceram seus companheiros na Colômbia. A incorporação de importantes chefes guerrilheiros na atividade política legal e democrática mudou a esquerda venezuelana e permitiu a consolidação de uma política de paz no país.

Os enormes ingressos petroleiros que chegaram ao país depois da crise petroleira de 1973, que triplicou em um ano os ingressos do governo central, permitiram fortalecer a política de pacificação. Quem se preocuparia de apoiar a luta guerrilheira quando havia tanto dinheiro na "Venezuela Saudita"? Os problemas que, a partir 
daí, se apresentaram, foram de outro tipo. Depois de 1975 apareceu no país um tipo de violência ligada aos delitos contra a propriedade, roubos a famílias, negócios e bancos. Esta era uma violência que não vinha da pobreza, mas da abundância. A Venezuela foi, num dado momento, o objeto de interesse de muitos delinqüentes nacionais ou importados: havia demasiado dinheiro aqui. Um assaltante menor de bancos que entrevistamos naquela época tinha um raciocínio impecável: $A$ expor minha vida em Barranquilla por cem mil pesos colombianos, é preferivel fazê-lo na Venezuela por cem mil bolívares venezuelanos, nos disse. Para esse momento, e trocada em dólares conversíveis, essa quantidade era muito mais dinheiro. $\mathrm{O}$ risco era parecido, mas o benefício muito maior.

Essa delinqüência, entretanto, não era particularmente letal. Havia aumentado o delito mas não a mortalidade, pois as taxas de homicídio não tinham aumentado de maneira significativa. Talvez fosse muito atraente e surpreendia as pessoas por sua espetacularidade e as quantias de dinheiro envolvidas. Mas, em um estudo que fizemos em uma zona do interior do país, achamos que a percepção de risco era muito maior que a realidade dos delitos conhecidos pela polícia ${ }^{15}$. E ainda, em meados dos anos 80, quando um grupo de universidades católicas dirigidas pelos jesuítas decidiu fazer um estudo multinacional sobre a violência, o comitê internacional duvidou bastante se a Venezuela era o cenário qualificado para o estudo, pois não lhe parecia que a violência fosse um problema importante nesse país. Pouco depois ficou demonstrado que era ${ }^{16}$.

\section{Os sonhos destruídos: 1983}

A partir de 1983 o país mudou para os venezuelanos. A Venezuela tinha tido livre convertibilidade da moeda e um sistema fixo de câmbio (um dólar por 4,3 bolívares) por cerca de 20 anos. Tal sistema fixo significava uma revalorização contínua da moeda nacional, pois, se bem que no âmbito interno a moeda perdia valor devido à inflação que, embora pequena, existia todo ano, no âmbito exterior conservava seu valor, uma vez que os produtos importados eram cada ano mais baratos que os nacionais. Em fevereiro de 1983, a situação tornou-se insustentável e a moeda foi desvalorizada, aplicando-se um estrito controle de câmbio em um dia que o país batizou de "Sexta-Feira Negra". A crise que se expressou nesse momento foi muito mais que uma medida de controle de câmbio, pois mostrou para os cidadãos as fragilidades daquele modelo de sociedade e dos sonhos de progresso duradouro que tinha alimentado ${ }^{17}$.

O salário real dos venezuelanos, que vinha em ascensão contínua desde os anos 50, deteve-se no começo dos anos 80 e, a partir daí, começou uma descida que ainda não se deteve. Para alguns autores a origem da crise surge quando, a partir de 1977, e depois da nacionalização do petróleo, paralisou-se a inversão privada no país ${ }^{18}$. Mas a população não começou a sentir as conseqüências em seus ossos e bolsos senão vários anos mais tarde.

A crise mexicana de agosto do ano de 1982 não foi compreendida como o anúncio de um conflito, como um presságio, mas como algo externo e próprio daquele país, que não poderia se repetir na Venezuela. A crise, que se tornou visível em 1983, esteve acompanhada de um período de retrocesso econômico na América Latina toda; uns anos de estancamento que muitos analistas tenderam a qualificar como a "década perdida".

Naquele ano de 1983, registrou-se na Venezuela uma taxa de 11 homicídios por cem mil habitantes. Como pode ser observado no gráfico 1 , essa cifra baixou levemente nos anos seguintes e se localizou ao redor de 10 homicídios em 1984 e 1985, e mais tarde em 8 homicídios nos anos 1986 e 1987. Tais taxas de homicídio eram muito semelhantes aos dos Estados Unidos da América do Norte e, embora não fossem tão baixas como as apresentadas por Costa Rica ou Argentina, eram realmente muito inferiores às que tinham a Colômbia ou El Salvador.

Esse período é entendido como os anos de incubação da violência. Foi nele que se deteve o processo de inclusão social e o crescimento constante da população cessou, o que não se expressou $^{19}$, porém, em crise social nem em violência, já que as pessoas ainda tinham reservas de dinheiro e de esperança que os problemas fossem transitórios e que brevemente retornariam à época de abundância dos fins dos anos 70 .

Talvez essa seja a razão pela qual as taxas de violência não cresceram na Venezuela tão cedo como ocorreu em outros países da América Latina, onde a causa surge vários anos antes, sem se importar se vinham de um período de muita violência, como na Colômbia, ou de pouca violência, como no Brasil. Na Venezuela, este é o período da surpresa social, de uma estupefação que paralisa e desconcerta, pois algo novo estava ocorrendo e as pessoas não sabiam como interpretá-lo. Alguns entenderam que uma crise maior se iniciava e, por isso, não somente se deteve a pressão migratória para a Venezuela, mas muitos imigrantes, tanto os antigos europeus, que estavam há várias décadas 
no país, como os do Cone Sul, chegados em anos anteriores, começaram um processo de retorno pessoal e de capitais. Outros preferiram manter a esperança de que se tratava apenas de um mau momento e não da crise mais séria que se anunciava ${ }^{20}$. Mas em 1988, o país mantinha a paz social e uma taxa de homicídios de um só dígito: 9 homicídios por cem mil habitantes.

\section{A violência social: 1989}

A campanha eleitoral de 1989 foi uma discussão imaginária que pretendia reviver os anos de abundância. O governo seguia empenhado em repetir o mesmo modelo distributivo e estatal, mas sem dispor dos recursos financeiros que o tinham feito possível. O governo de J. Lusinchi (1984-1989) mantinha uma política de controle artificial de preços que impulsionava a corrupção e provocava enorme apropriação indevida e escassez de produtos básicos como o leite, o açúcar ou toalhas sanitárias femininas. A segunda eleição de Carlos Andrés Perez (1988) foi uma notável manipulação das boas lembranças da época da abundância que serviram para ganhar as eleições. Mas o presidente demonstrou muito rapidamente, e já no governo, que estava disposto a romper com o passado, ou seja, com o domínio do aparelho burocrático pelo partido e com a economia rentista e petroleira.

Mas o início de gestão foi de muito conflito. A tensão social causada pela permanente escassez de produtos, bem como o contraste entre a imagem que tinham feito os eleitores de um candidato populista e distribucionista e as primeiras medidas econômicas do governo provocaram a revolta social mais importante do século. A sensação que existia em muitas pessoas era de que a riqueza tinha acabado e que alguns se tinham apropriado dela e, conseqüentemente, era bom se apossar do pouco que restava.

Os saques de 27 e 28 de fevereiro de 1989 foram violentos tanto na sua forma, o uso da força para romper as portas dos negócios e saquear o que encontrasse, como na resposta repressiva por parte dos organismos de segurança e do exército.

Muitas cifras foram dadas naquele momento sobre o número de mortos durante os dias da revolta, chegando-se a calcular em vários milhares de pessoas. Fizemos um estudo com os dados do necrotério de Caracas e pudemos contabilizar 534 mortos naqueles dias ${ }^{21}$. Os resultados que encontramos eram muito inferiores às especulações feitas pela imprensa, mesmo assim, muito altos. Sempre é possível que algumas mortes tenham ficado sem registrar. Mas se pensarmos que nos anos anteriores ocorriam uns 1.500 homicídios em todo o país, durante um ano completo, a cifra de 500 mortos somente em Caracas, em menos de uma semana, era extremamente elevada.

As mortes ocorreram das maneiras mais variadas possíveis. Houve pessoas mortas por alguns comerciantes que tentavam defender suas propriedades; houve mortos entre os próprios saqueadores, delinqüentes profissionais que disputavam algum butim cobiçado, pessoas comuns que simplesmente caíram de uma escada no meio de uma 
fuga e pereceram de traumatismos múltiplos, pessoas mortas em enfrentamentos com o exército. E houve também casos ao acaso, como o de uma senhora que presenciava tranqüilamente uma briga da sacada de sua casa, localizada num $13^{\circ}$ andar, e que caiu morta, ao lado da filha adolescente, alcançada por uma bala perdida.

A taxa de homicídios no ano 1989 subiu 4 a 5 pontos para alcançar 13,5 mortes por cem mil habitantes, isto é, um aumento de 50\% em relação ao ano anterior.

Como pode ser visto no gráfico 1 , a taxa de homicídios baixou levemente nos anos seguintes, de 1990 e 1991, quando foi de 12,5 e 12,4, respectivamente, não retornando, porém, para o nível de 1988.

A gente se pergunta: o que foi que deteve aquela estranha orgia, aquela ruptura abrupta do pacto social que eram os saques? Alguém pode pensar que foi a ação repressiva do exército; no entanto, tenho a impressão de que as próprias pessoas foram as que puseram fim à escalada. Nos bairros pobres a desordem intimidou as pessoas, $\mathrm{e}$ as famílias de menor ingresso tiveram também medo de ser vítimas dos saques. Era um medo prático, mas, ao mesmo tempo, um medo simbólico que se expressa no temor à loucura, pois os saques sem controle são vividos como uma espécie de loucura, enquanto representam uma ruptura do pacto social e da ordem simbólica.

\section{Os golpes de Estado: 1992}

Outra ruptura importante do pacto esteve representada pelas tentativas de golpe de Estado de 1992, neste caso, tratando-se do pacto político e da ordem simbólica que representa a democracia, tendo também suas conseqüências importantes na violência.

De um modo paradoxal, o mesmo presidente da república que tinha conduzido a exacerbação do modelo petroleiro rentista nos anos 70, C.A. Pérez (1974-1979), foi quem empreendeu quinze anos depois a única proposta importante da transformação do governo (1989-1993). Era uma ruptura com o sistema de renda e uma possibilidade de se construir uma sociedade não petroleira, não distribucionista e não estatista. A proposta podia e pode ser criticada a partir de muitos ângulos, no entanto, até o momento presente, incluindo Chávez e seus inflamados revolucionários, é a única vez que, a partir do governo, se postulou uma verdadeira mudança na economia e na sociedade venezuelanas. Mas tal proposta foi derrotada pela mentalidade rentista e caudilhista que prevaleceu no país.
Os golpes de Estado de fevereiro e novembro de 1992 mostraram o rosto da violência política e geraram uma crise institucional que viria incrementar a violência delinqüencial muito além do ano e dias dos atentados. As tentativas de golpes de Estado provocaram, por si mesmas, mortes violentas entre os militares que participaram nos enfrentamentos, bem como no seio da população civil, mas os homicídios não terminaram aí, pois a crise de legitimidade que provocaram foi demasiado grande. E ao romper-se o pacto simbólico, os delinqüentes ou as pessoas comuns se sentiram mais liberadas para o uso da violência.

No ano de 1992, a taxa de homicídios alcançou a cifra de 16,3 mortes por cem mil habitantes, 4 pontos mais do que no ano anterior. Nos anos 1990 e 1991 tinham sido registrados no país 2.474 e 2.502 homicídios respectivamente, isto é, um volume quase idêntico. Mas em 1992, houve um salto e se elevaram a 3.366, quer dizer, 866 homicídios a mais, o que representou $34 \%$ de aumento de um ano para o outro. Mas, como pode ser observado na tabela 1, o impacto dos golpes de Estado na violência foi além, pois não se deteve quando os militares rebeldes foram derrotados e detidos, mas continuou elevando-se nos anos seguintes, a ponto de, em 1993, registrarem-se 4.292 assassinatos para uma taxa de 20,3 homicídios por cem mil habitantes. Isso significa que voltou a subir 4 pontos, e voltou a elevar-se em 1994, quando foram cometidos 4.733 homicídios e se chegou a uma taxa de 22 homicídios por cem mil habitantes.

Em resumo, pode-se dizer que, entre os golpes de Estado de 1992 e o início do governo de R. Caldera (1994-1999), os homicídios no país quase se duplicaram em números absolutos. Levando em conta o crescimento populacional, podemos expressá-lo dizendo que a taxa de homicídios passou de 12 a 22 vítimas por cem mil pessoas. Isto não pode ser casualidade, a crise política desses anos e a ruptura do pacto social da democracia, que significou o uso das armas para tentar mudar o governo, tiveram conseqüências muito graves na violência quotidiana. Em um par de anos deuse a destituição do presidente da república e a nomeação de dois presidentes e dois governos provisórios num clima de incerteza gerado por ameaças de novos golpes de Estado.

Nesse período, foi superada a barreira dos quatro mil homicídios por ano no país e acenderam-se as luzes de alarme sobre um fenômeno social novo que estava ocorrendo na Venezuela. A violência tornava-se um problema que já não era pontual, já não era um instante ou um dia de raiva e rebeldia, mas que afetava regularmente a vida quotidiana 


\section{Tabela 1}

Homicídios na Venezuela 1990-2003.

\begin{tabular}{lccc}
\hline & $\begin{array}{c}\text { Total de } \\
\text { homicídios }\end{array}$ & $\begin{array}{c}\text { População } \\
\text { (em milhões) }\end{array}$ & $\begin{array}{c}\text { Taxa por } \\
\text { 100.000 habitantes }\end{array}$ \\
\hline 1990 & 2.474 & 19.7 & 12.53 \\
1991 & 2.502 & 20.1 & 12.38 \\
1992 & 3.366 & 20.6 & 16.29 \\
1993 & 4.292 & 21.1 & 20.32 \\
1994 & 4.733 & 21.5 & 21.92 \\
1995 & 4.481 & 22.0 & 20.32 \\
1996 & 4.961 & 22.9 & 22.04 \\
1997 & 4.225 & 23.4 & 18.40 \\
1998 & 4.550 & 23.4 & 19.43 \\
1999 & 5.974 & 23.8 & 25.02 \\
2000 & 8.021 & 24.3 & 32.99 \\
2001 & 6.432 & 24.7 & 25.97 \\
2002 & 9.244 & 25.2 & 36.65 \\
2003 & 13.288 & 26.0 & 50.96 \\
2004 & Proibida a publicação & & \\
\multicolumn{1}{c}{ da informação } & & \\
\hline
\end{tabular}

Fonte: LACSO Cálculos próprios sobre Corpo de Pesquisas Científicas Penais e Criminalísticas, Instituto Nacional de Estatística

das pessoas ${ }^{22}$. Foi aí que a Organização PanAmericana da Saúde decidiu incluir a Venezuela no estudo que desenvolvia sobre normas e atitudes sobre a violência. Durante esses anos, os caraquenhos começaram a ter medo dos inocentes fogos artificiais, pois toda vez que os escutavam pensavam que se tratava de um novo levante militar.

A partir de 1995 produziu-se uma estabilidade transitória no país. As eleições de 1994 mostraram que o pacto democrático continuava funcionando e que era possível uma mudança de governo de maneira eleitoral e pacífica, mas os partidos políticos passavam por uma profunda crise ${ }^{23}$. Nessas eleições, o país tomou um caminho muito estranho, pois decidiu votar por uma mudança política segundo a qual, para derrotar os candidatos jovens dos dois partidos que por 40 anos tinham partilhado o poder, foi escolhido o candidato de maior idade e que melhor representava a política tradicional do país: R. Caldera. Quer dizer, o candidato que, de maneira objetiva, era o maior representante do passado, foi assumido pela população como o mensageiro do novo. A população quis votar contra os partidos e para isso valeu-se do melhor representante vivo dos partidos tradicionais e fundador de um deles.

O governo de Caldera (1994-1999) não representou nenhuma mudança social ou política importante, mas devolveu estabilidade ao país. $\mathrm{O}$ pacto social recuperou vigência e isso se traduz numa estabilização das relações sociais e dos con- flitos políticos. Se voltamos a olhar o gráfico 1, poderemos notar que a linha que mostra a taxa de mortes estabiliza-se e oscila ao redor dos 20 homicídios durante todo este período e o número total de assassinatos diminuiu em quase todos os anos desse período (exceto em 1996). E, se a este fato é somado o crescimento normal da população, achamos que ocorreu inclusive um leve decréscimo nas taxas de homicídios nos anos 1997 e 1998 . O país tinha conseguido superar os traumatismos dos golpes de Estado e da crise bancária, mas os danos para a legitimidade da democracia e da divisão social já estavam consumados.

\section{A revolução bonita: 1999}

Tem-se a impressão de que o país estava procurando um caudilho salvador desde os anos 80 . No fundo, talvez estivesse buscando uma figura que restituísse as benesses do modelo petroleiro, pois não podia aceitar - e isto é verdade para todos os setores sociais - sua inviabilidade e seu fracasso. Também não se atrevia a enfrentar os desafios e angústias do novo. Qual, senão esta, pode ser a explicação das escolhas eleitorais? Os segundos governos de C.A. Pérez (1989-1993) e de R. Caldera (1994-1999) foram uma tentativa ilusória de mudar os males de um presente com a nostalgia dos melhores tempos passados. Como se fosse a vontade dos líderes e não as duas realidades 
econômica e política as que determinam o bom e o mau do caminho. É claro, os líderes sempre podem fazer as coisas piorarem.

A partir de 1999 deslanchou-se uma crise política na Venezuela que ainda não terminou. Os homicídios têm aumentado num volume tal que analista algum poderia imaginar. Quando o tenente-coronel Chávez andava em campanha eleitoral no ano de 1998, cometeram-se 4.550 homicídios em todo o país. Seis anos depois do seu governo, houve 13.288 homicídios, quase três vezes mais. A taxa de homicídios, que em 1998 era de 19,5 por cem mil habitantes, passou para 51 homicídios por cem mil habitantes no ano 2003, isto é, um acréscimo de 20 pontos, sem que então houvesse uma declaração formal de guerra. Trata-se de um crescimento abismal e um comportamento da curva que tecnicamente não poderia ser qualificado como tendência normal. O que se passou nesses anos?

Por um lado, a crise política empurrava a violência e, por outro, o governo impedia o seu controle e repressão. E o fazia de todas as formas possíveis. Isto é, com intenção ou sem ela, como uma estratégia política ou como uma conseqüência indesejável, os resultados são visíveis.

O governo de Chávez tem mantido um discurso e uma política ambíguos diante do delito e da violência. Ou poderíamos dizer que ele tem mantido duas políticas. Quando Chávez foi eleito, misturavam-se nele as figuras do militar e do revolucionário e, embora não parecesse lógico, para muitas pessoas representava ao mesmo tempo um desejo de mudança e uma aspiração de ordem; a possibilidade de se transformar o país, mas, igualmente, de obter segurança e aplicar "mão dura" aos delinqüentes. Sua imagem de militar favorecia a idéia da mão dura que, por tempos, fora procurado; seu comportamento transgressor inspirava a possibilidade de mudança.

Essa dualidade tem se mantido nas políticas do governo: por um lado, há uma política tolerante e até permissiva para com o delito, e o próprio presidente tem falado repetidas vezes que "é compreensível que a gente roube se tem necessidade". Mas, por outro lado, há uma política repressiva violenta que levou um vice-ministro de segurança cidadã a declarar, orgulhosamente, que durante aquele ano a polícia tinha eliminado mais de dois mil "pré-delinqüentes". Uma novidade nos conceitos do direito penal que não existia na legislação venezuelana.

Todavia, há políticas que favorecem a violência. Uma delas tem sido o descrédito sistemático ao qual foi submetida a polícia e que levou tanto para uma campanha de agressões e desqualificações verbais, como as medidas de desarmamento dos funcionários. No ano 2002, a emissora de televisão do governo transmitiu sistemática e repetidamente a promoção do filme venezuelano intitulado Disparem para matar, como sempre fazem os canais de TV quando estão preparando a audiência para uma estréia. Nas cenas escolhidas do filme para os comerciais, apresentava-se um oficial de polícia ordenando morbidamente a repressão em um bairro pobre; depois mostravase o crime cometido por um funcionário da polícia num rincão escuro; após um som estrepitoso do disparo, escutava-se o grito raivoso e longo da mãe da vítima que acusava os policiais: "Assassinos!" Antes e depois da propaganda, agregavamse frases políticas contra a oposição política do governo. Por muito tempo difundiu-se a propaganda, mas nunca era anunciado quando o filme seria projetado; alguns meses depois marcou-se uma data, mas, nem nesse dia nem nos seguintes, o filme foi passado. A intenção, segundo parece, era outra.

Isso não parece ser casualidade. Em diversas oportunidades o presidente da república tem se dedicado a contradizer uma velha crença popular venezuelana. Por décadas, ensinou-se às crianças venezuelanas que "a violência é a arma dos que não têm razão". A expressão tem sido difundida como um valor destinado a desestimular a maneira violenta de resolução de conflitos entre os grupos de menores de idade nas escolas e vizinhanças, embora também entre as pessoas adultas, sobretudo na passagem da vida rural para a vida urbana. Tem sido surpreendente observar como, nos longos discursos de várias horas por todas as rádios e todos os canais de TV, o presidente tem falado várias vezes que tal afirmação "não é verdade", sugerindo que a violência pode ser usada e procurando mudar uma idéia que ele sabe fortemente arraigada na população.

Não é de se estranhar, então, que em 1999 se atingisse 5.974 homicídios, que no ano 2002 chegaram a 9.244 e que em 2003 superaram as 13 mil vítimas. Quer dizer, os homicídios triplicaram em seis anos da chamada "revolução bonita".

\section{O silêncio dos mortos: 2004-2005}

O leitor atento pergunta: "E por que o autor não usa os dados de homicídios dos anos 2004 e 2005?" A resposta é simples e triste: os dados oficiais desses anos não foram dados a conhecer pelas autoridades. Pela primeira vez na história recente, 
os dados de homicídios não estão disponíveis para a opinião pública, nem para a imprensa ou para os pesquisadores. Simplesmente não sabemos o que sucedeu com os homicídios naqueles anos. Quem sabe algum funcionário pensaria que os homicídios terminariam se a imprensa não publicasse, nem os pesquisadores os estudassem. A medida deve ser julgada por todos. Em nossa opinião, somente podemos dizer que isso parece confirmar o pior, quer dizer, que o aumento deve ter sido muito grande pois, se assim não fosse, por que ocultá-lo?

O desaparecimento das estatísticas de homicídios leva a vitimização a um nível superior. Deseja-se submeter as vítimas a um silêncio ainda maior, deseja-se torná-las algo mais do que anônimos: já perderam sua vida e seu nome, agora nem sequer podem ser cifras. No entanto, podemos dispor de alguns dados não-oficiais para o ano 2004, pois o Laboratório de Ciências Sociais, LACSO, conjuntamente com o Instituto de Ciências Penais da Universidade Central de Venezuela e o Instituto de Criminologia Lolita Aniyar de Castro, da Universidade del Zulia, levam a cabo um inquérito em que um dos componentes era a vitimização relatada pelos entrevistados 24 .

A tabela 2 mostra os resultados do inquérito: a quarta parte da população maior de 18 anos de idade declarou ter sido vítima de roubo ou algum outro ato violento (seqüestro, extorsão, ameaça). A cifra é bastante alta, mas chamam a atenção dois detalhes: por um lado, a quase totalidade dos homicídios é informada, a porcentagem não denunciada pode ocorrer, pois os homicídios são fatos públicos que não precisam de denúncia para a atuação da polícia. Por outro lado, destaca-se que somente a terça parte (35\%) dos atos de violência não-fatal são denunciados para as autoridades, o que indica pouca confiança no sistema policial e penal. Um segundo aspecto que merece atenção é a composição dos infratores, pois tanto nos homicídios como nos roubos uma quinta parte deles eram conhecidos das vítimas, o que indica a proximidade da violência numa proporção importante dos casos. O outro que pode ser destacado é a alta porcentagem de casos nos quais os homicídios tinham sido cometidos por autoridades policiais ou da Guarda Nacional (uma dependência das forças armadas com funções de segurança pública). Não se pode concluir dos dados do inquérito se estes fatos ocorreram em cumprimento de suas funções ou em ações extrajudiciais, mas, em qualquer caso, acentua a idéia de uma intensificação importante da violência policial.

\section{Tabela 2}

Venezuela 2004. Vitimização, identidade do infrator e denúncia do fato (Amostra nacional, no 1202).

\begin{tabular}{lcc}
\hline & $\begin{array}{l}\text { Algum familiar próximo } \\
\text { foi assassinado nos últimos } \\
12 \text { meses (\%) }\end{array}$ & $\begin{array}{l}\text { Foi vítima de um roubo } \\
\text { ou ato violento nos } \\
\text { últimos 12 meses (\%) }\end{array}$ \\
\hline $\begin{array}{l}\text { Vitimização (\% resposta positiva) } \\
\text { Quem era o assassino ou o infrator? }\end{array}$ & 3,0 & 24.6 \\
\hline Um amigo & 19.4 & 22.8 \\
Um familiar & 5.6 & 2.0 \\
Um desconhecido & 55.6 & 72.8 \\
Polícia ou Guarda Nacional & 16.7 & 35.0 \\
$\begin{array}{l}\text { Denunciou o fato para as autoridades? } \\
\text { (\% resposta positiva) }\end{array}$ & 91.7 & \\
\end{tabular}

Fonte: LACSO - Inquérito Nacional de Violência e Justiça Penal 2004. 


\section{Para onde vai a Venezuela?}

O que ocorrerá com a violência? Quais são os riscos agora? Parece que todos os cenários apontam para mais violência na Venezuela.

O governo de Chávez representa um passo a mais na exacerbação do modelo rentista petroleiro, o mesmo que vinha se debilitando desde os anos 80 e que, repentinamente, teve um novo oxigênio com o incremento notável dos preços do petróleo a partir de 2003. O modelo estatista e distribucionista se acentuou. O primeiro - o estatismo - está sendo favorecido pela personalidade e as ambições autoritárias do presidente e, o segundo - o distribucionismo -, pelos ingressos que de maneira abundante chegam para o governo central. O modelo não é novo, é o mesmo que tem submergido a Venezuela em mais pobreza e mais violência.

Talvez os defensores de H. Chávez possam alegar algumas mudanças reais, pois é verdade que a elite anterior no poder foi afastada e substituída por outra nova que, no entanto, não demonstrou ser melhor. Tem havido uma mudança de atores, de nomes, mas não de procedimentos. As instituições não têm melhorado, mas piorado. Por exemplo, um procedimento institucional importante na transparência da gestão do governo em quase todos os países são as licitações para assinar contratos para as empresas e pessoas que oferecem produtos ou serviços para o Estado. Na Venezuela existia uma lei que regulava as licitações e fixava as normas sobre como, de maneira pública, as empresas podiam competir pelos contratos. $\mathrm{Na}$ atualidade, as licitações, os concursos, foram eliminados e o Ministro ou chefe responsável decide, sem nenhum regulamento além da sua vontade, para quem os contratos são entregues. Não é de se estranhar o notável aumento da corrupção.

Também é possível reconhecer que têm sido aumentados os recursos diretamente oferecidos para os setores pobres da sociedade, mas isso não muda nada substancial, pois o modelo é o mesmo. Os mecanismos populistas já existiam há várias décadas, talvez num volume menor, pois tinham menos recursos. Todavia é o mesmo distribucionismo da renda petroleira do passado, só que com um regime militar e autoritário que ostenta outros símbolos, que oferece benesses distintas e emprega outra linguagem.

Com a estratégia populista de presentear dinheiro dentro e fora do país, o governo de Chávez conseguiu se estabilizar, e isto deveu-se ao fato de que, quando estava em campanha eleitoral, o preço do petróleo estava em oito dólares o barril, e no começo de 2006 superava 50 dólares, o que representa um orçamento seis vezes superior ao de seu primeiro ano de governo e o mais alto da história de Venezuela.

Mas a possibilidade real de se consolidar como regime hegemônico somente pode passar pelo emprego de maior repressão e violência a uma sociedade e a uns setores pobres que protestam, movidos pelas expectativas exacerbadas pelas contínuas promessas presidenciais, e insatisfeitas pela precária gestão do seu governo. Quanto de violência será necessário empregar para conter a oposição política e o protesto social é difícil de prever. Mas é muito surpreendente que a nova Lei das Forças Armadas da Venezuela tenha previsto um braço armado de reservistas, que tem funções de "segurança interna" e depende diretamente do presidente da República e não do ministro da Defesa.

Outra vertente da violência tem a ver com a possibilidade de um enfrentamento bélico com outros países, em particular com a anunciada guerra com os Estados Unidos da América. A doutrina militar venezuelana foi modificada para incluir os EUA como o inimigo principal, e estabelece planos para uma guerra chamada "assimétrica" ou de "quarta geração", que prevê, segundo anúncio presidencial de janeiro de 2006, o armamento de um milhão de civis com fuzis AK-47.É possível que tudo isso seja apenas fanfarronices e formem parte das campanhas de distração política. Mas, na prática, essas mensagens fomentam a violência, pois estão rompendo o pacto social que sempre a contém.

Há outro cenário político que também sugere violência: a debilitação do regime, com a perda de apoio e controle e que, quer eleitoralmente, quer por uma ação militar, se produza uma mudança no poder. A transição eleitoral, ainda que não impossível, não parece poder se realizar facilmente nas condições políticas da Venezuela. Uma mudança, produto de uma ação militar, não é desejável, mas também não é impossível, uma vez que se fecham os caminhos eleitorais e aumentam o descontento e a segregação política. Mas os dois cenários fazem prever mais violência política, pois, que outra coisa pode fazer com que o governo resista a entregar o poder eleitoralmente ou que o mesmo seja arrebatado por meio de um golpe militar?

Num contexto de violência política como a que descrevemos, a violência delinqüencial, a violência das gangues e da polícia tenderão a se intensificar de modo notável, pois os indivíduos violentos encontrarão um espaço de fácil atuação e isso é o que já está acontecendo nestes últimos anos. Foi o que ocorreu logo após a revolta de fevereiro de 1989, quando se deu o primeiro aumento de homicídios; é o mesmo que 


\section{Referências}

1. Irazabal C. Venezuela, esclava y feudal. Caracas: Editorial Ateneo; 1980.

2. Malave Mata H. Petróleo y desarrollo económico de Venezuela. Caracas: Ediciones Pensamiento Vivo; 1962.

3. Carrillo Batalla TE. La dinámica del desarrollo económico venezolano. Rev Latinoam Econ 1965; 17:45-68.

4. Araujo O. Situación industrial de Venezuela. Caracas: Ediciones de la Biblioteca de la Universidad Central de Venezuela; 1969.

5. Gabaldón A. Una política sanitaria. Caracas: Ministerio de Sanidad y Asistencia Social; 1965.

6. Martz JD, Myers DJ. Venezuelan democracy: perfomance and prospects. In: Martz JD, Myers DJ, editores. Venezuela: the democratic experience. New York: Praeger Publishers; 1986; p. 437-67.

7. Briceño-León R. Los efectos perversos del petróleo. Caracas: Fondo Editorial Acta Científica Venezolana, Consorcio de Ediciones Capriles; 1991.

8. Briceño-León R. Petroleum and democracy in Venezuela. Soc Forces 2005; 83(1):1-30.

9. Baptista A. El estado y el capitalismo rentístico. Caracas: Academia Nacional de la Historia; 2005.

10. Ricardo D. Des principes d'économie politique et de l'impôt. Paris: Flammarion; 1977.[1 $1^{\text {a }}$ ed. 1821].

11. Marx K. 1968. El capital. México: Fondo de Cultura Económica; 1968. [1 $1^{\text {a }}$ ed. 1867].

12. Baptista A. Teoría económica del capitalismo rentístico. Caracas: Ediciones Iesa; 1997.

13. Furtado C. El desarrollo reciente de la economía venezolana. In: Valecillos H, Bello O, compiladores. La economia contemporánea de Venezuela. Caracas: Banco Central de Venezuela; 1990. p. 165-206.

14. Cordova A. La estructura económica tradicional y el impacto petrolero en Venezuela. Revista Economía y Ciencias Sociales 1963; 5(1):7-28.

15. Briceño-León R. Venezuela: clases sociales e individuos. Caracas: Fondo Editorial Acta Científica Venezolana, Consorcio de Ediciones Capriles; 1992.

16. Ugalde L. La violencia en Venezuela. Caracas: Monteavila Universidad Católica Andres Bello; 1990.

17. Venezuela. Banco Central. Informe Económico. Caracas: BCV; 1975,1985, 2004.

18. Baptista A. El relevo del capitalismo rentístico: hacia un nuevo balance del poder. Caracas: Fundación Polar; 2004.

19. Marquez G.Venezuela: poverty and social policies in the 1980s. In: Lustig N, editor. Coping with austerity: poverty and inequality in Latin America.Washington, D.C.: The Brookings Institution; 1995.

20. Berglund S. La población extranjera en Venezuela de Castro a Chávez. In: Las inmigraciones a Venezuela en el siglo XX. Caracas: Fundación Francisco Herrea Luque; 2005; p. 35-50

21. Briceño-León R. Contabilidad de la muerte. In: El Nacional, organizador. Cuando la muerte tomó la Calle. Caracas: Editorial Ateneo; 1990.

22. Sanjuan A M. La criminalidad en Caracas: percepciones y realidades. Rev Venezolana Econ Ciencias Soc 1997; 3(2-3):215-54.

23. Molina JE. Partidos y sistema de partidos en la evolución política venezolana: la desinstitucionalización y sus consecuencias. In: Molina JE, Álvarez AE, coordenadores. Los partidos políticos venezolanos en el siglo XXI. Caracas: Vadell Editores; 2004; p. 9-56.

24. Laboratorio de Ciencias Sociales. Instituto de Ciencias Penales de la Universidad Central de Venezuela y el Instituto de Criminología Lolita Aniyar de Castro de la Universidad del Zulia.Encuesta Nacional deViolencia Urbana y Sistema de Justicia penal. Caracas; 2004.

25. Briceño-León R. Urban violence and public health in Latin America: a sociological explanatory model. Cad Saúde Publica 2005; 21(6):1629-64.

26. Venezuela. Ministerio de Interior y Justicia. Archivos de Dirección de Prevención del Delito. Caracas: MIJ; 2004.

27. Venezuela. Ministerio de Planificación y Desarrollo. Instituto Nacional de Estadística. Proyecciones de de población. Caracas: MPD; 2004.

Artigo apresentado em 28/03/2006

Aprovado em 31/03/2006

Versão final apresentada em 14/04/2006 